EGU21-6701

EGU General Assembly 2021

(c) Author(s) 2021. This work is distributed under

the Creative Commons Attribution 4.0 License.

\title{
Provenance Determination of Paleochannel Infillings in the Alsatian Upper Rhine Floodplain Using Mid-Infrared Spectroscopy- Discriminant Analysis
}

\author{
Mubarak Abdulkarim ${ }^{1,4}$, Stoil Chapkanski ${ }^{2}$, Damien Ertlen ${ }^{3}$, Claire Rambeau ${ }^{3}$, Laurent Schmitt ${ }^{3}$, \\ Louis Le Bouteiller ${ }^{3}$, and Frank Preusser ${ }^{1}$ \\ ${ }^{1}$ Institute of Earth and Environmental Science, University of Freiburg, Germany (mubarak.abdulkarim@geologie.uni- \\ freiburg.de) \\ ${ }^{2}$ Laboratory of Physical Geography (LGP), UMR 8591, University Paris 1, Pantheon-Sorbonne - CNRS, Paris France \\ ${ }^{3}$ Laboratoire Image Ville Environnement (LIVE), UMR 7362, University of Strasbourg-CNRS-ENGEES, Strasbourg, France \\ ${ }^{4}$ Department of Geology, Federal University Birnin Kebbi, Kebbi, Nigeria
}

The Alsatian Upper Rhine floodplain (northeastern France) is characterized by a complex anastomosing network of paleochannels inherited from Late Glacial braided fluvial pattern of the Rhine system. These paleochannels are filled by mixed or stratified clastic and organic sediments originating from different sediment sources. Identifying these sediments' provenance is critically important for understanding past surface processes and reconstructing the Upper Rhine Valley evolution in the course of the Holocene. This study employed mid-infrared spectroscopy to determine the source of sediments and, therefore, understand which rivers may have contributed to the paleochannel infilling and establish the main patterns of filling through time. Sediment samples with unknown sedimentary provenance were collected in 16 sites consisting of paleochannels and the III River's levees. Mid-Infrared spectroscopic analyses were carried out on powdered $(<2 \mathrm{~mm}$ ) samples using a Frontier Spectrometer (PerkinElmer) equipped with Diffuse Reflectance Infrared Fourier Transform accessory. Statistical analysis (Discriminant Analysis - DA) was performed to compare the spectral signatures obtained from the samples and a previously established reference spectral dataset (Chapkanski et al. 2020) covering potential sediment sources in the Upper Rhine area (the Rhine, III, and Vosges tributaries). The results showed wellcontrasted sediment sources, with multiple rivers contributing to the paleochannel infilling history. The sediments were found to originate from the Rhine and III River systems and, to a lesser extent, Vosges tributaries. Some channels have an exclusively Alpine Rhine catchment origin while others showed purely III signatures. However, for most of the channels, infilling sources changed over time, presenting a relatively complex mixture of multiple sediment sources, indicating the lateral shifting of the two rivers within the alluvial plain. The results confirm that Mid-infrared spectroscopy (MIRS), combined with discriminant analysis, can give highly-specific determinations to sediments' sources. Thus MIRS-DA technique shows the potential of its being applicable as a rapid, low-cost, and efficient alternative method for provenance analysis of fluvial deposits in large, complex floodplains. 